- Original Article

\title{
Fear of Falling and Mortality among Older Adults in Korea: Analysis of the Korean Longitudinal Study of Aging
}

\author{
Ari Lee, Jungun Lee*, Gyumin Lee, Dong Ryul Lee \\ Department of Family Medicine, Wonkwang University Sanbon Hospital, Wonkwang University School of Medicine, Gunpo, Korea
}

\begin{abstract}
Background: The fear of falling (FOF) has been reported in a high percentage of elderly people. An excessive FOF is a major concern among the elderly because it can lead to permanent disability. However, the impact of FOF on mortality has been insufficiently studied. The aim of this study was to investigate the impact of FOF on mortality among the elderly in Korea.

Methods: This was a prospective study carried out using the database of the Korean Longitudinal Study of Aging, a nationwide study of community-dwelling adults in Korea. Study participants included 3,421 adults, aged 65 years or older, without either severe cognitive impairment (Korean version of Mini-Mental Status Examination $\geq 10$ ), or previous history of cancer. We used Cox proportional hazards models to investigate the association between FOF and all-cause mortality.

Results: This study included 1,474 men and 1,947 women. Cox regression showed that participants with FOF had an increased risk of mortality (mild: hazard ratio [HR], 1.25; 95\% confidence interval [CI], 1.01-1.54; moderate: HR, 1.59; 95\% CI, 1.23-2.05) after adjusting for confounding variables. In a subgroup analysis, FOF was still a significant risk factor of mortality for patients with no previous history of falling after adjusting for other risk factors, as in the full model, except for history of falling (HR, 1.65; 95\% CI, 1.27-2.13).

Conclusion: We found that FOF was a significant risk factor for mortality in the elderly in Korea. Further studies on the effects and mechanism of FOF on mortality are needed.
\end{abstract}

Keywords: Fear; Accidental Falls; Mortality; Aged

Received: August 1, 2018, Revised: September 14, 2018, Accepted: September 27, 2018

*Corresponding Author: Jungun Lee https://orcid.org/0000-0001-8580-1445

Tel: +82-31-390-2416, Fax: +82-31-390-2266, E-mail: tracheo@wku.ac.kr 


\section{INTRODUCTION}

Fear of falling (FOF) is defined as an excessive concern about falling or the belief that one cannot prevent a fall. Many older individuals, both fallers and non-fallers, suffer from a variety of adverse psychosocial difficulties related to falling, including fear, anxiety, loss of confidence and impaired self-efficacy resulting in activity avoidance, social isolation, and increasing frailty. ${ }^{1-6)}$ FOF is a common and disabling problem in older individuals and was reported in $3 \%-85 \%$ of communitydwelling elders who have fallen and up to $50 \%$ of those who have never fallen. ${ }^{1,2,5,6)}$

The prevalence of FOF and consequent adverse effects differ in studies. In a study of over 1,000 community-dwelling women aged 70 to 85 years, FOF, as determined by a questionnaire, was found in onethird of women at baseline and affected $46 \%$ of the sample during the 3-year follow-up. ${ }^{1)}$ In a study of 673 community-dwelling older adults, $60 \%$ reported moderate restriction of activity and $15 \%$ severe restriction of activity due to $\mathrm{FOF}^{7)}$ A systematic review found that FOF may affect $50 \%$ or more of patients following hip fracture. ${ }^{8)}$

Many cross-sectional studies have focused on the risk factors of FOF. ${ }^{9)}$ Previous studies have shown that old age, female sex, a history of previous falls, decreased cognitive function, impaired physical performance, depressive disorders, and chronic illness were associated with FOF. $^{1,5,10-13)}$ It has also been associated with restriction in activity, decreased life satisfaction, and frailty. ${ }^{5,7,12)}$ A number of previous studies have used a cross-sectional design to evaluate the associated factors of FOF. Although there have been several follow-up studies, the focus is limited to changes in daily activities, functional abilities, and quality of life caused by FOF. ${ }^{1,7,10,11)}$ However, the impact of FOF on mortality has not been extensively studied, because a large population sample and the changes to it over time are required to investigate the relationship between FOF and mortality. Therefore, the aim of this longitudinal prospective study was to investigate the impact of FOF on mortality among community-dwelling older adults using the database of the Korean Longitudinal Study of Aging (KLoSA).

\section{METHODS}

\section{Data and Study Sample}

This study was based on the database of the KLoSA. ${ }^{14)}$ The KLoSA is an ongoing longitudinal panel survey of community-dwelling adults in Korea aged $\geq 45$ years. It was first conducted in 2006 , with biennial follow-up, and the sixth survey, started in 2016, is currently in progress. This biennial survey involves multistage, stratified sampling based on geographic areas. The KLoSA survey includes questionnaires on demographics, health status, marital status, employment status, and annual household income. In the first baseline survey in 2006, 10,254 participants from 6,171 households were interviewed by trained interviewers using the computer-assisted personal interviewing methods. In 2014, the fifth survey followed up with 7,467 subjects, who represented $72.8 \%$ of the original panel. The KLoSA also includes data on deaths. Since 2008, deaths have been reported at intervals of 2 years; the date, cause and place of death, and the past medical history of the dead are collected.

Our study analyzed the 2006 baseline interview data of 3,421 participants aged 65 or older without severe cognitive impairment at the time of the survey. All participants provided written informed consent, and the survey protocol was approved by the Institutional Review Board of Statistics Korea. Among the 10,254 participants of the KLoSA in 2006, 6,413 were excluded due to age ( $<65$ years) and severe cognitive impairment (Korean version of Mini-Mental Status Examination [KMMSE] score <10). Participants with insufficient data on survival $(n=314)$ and those who had been diagnosed to have cancer $(n=106)$ were also excluded. To investigate the association between FOF and all-cause mortality among these individuals, we finally included 3,421 (1,474 men and 1,947 women) study subjects at baseline. During the 8-year follow-up period, 705 subjects died (20.6\%), of which 388 (55.0\%) were men and 317 (45.0\%) were women.

\section{Measurements}

The education level was classified based on the final education level as elementary school, middle school, high school, and college. Marital status was categorized as living with and not living with a spouse, the latter of which included divorce, bereavement, and separation for a variety of reasons, such as long-term accommodation and long stays abroad. Subjects with chronic illness were assessed for the presence of hypertension, diabetes mellitus, chronic lung disease, chronic liver disease, heart disease, and stroke. Subjects were classified according to smoking status as non-smokers, former smokers, and current smokers. Former smokers were defined as those who do not smoke at present but have consumed more than five packs of cigarettes in the past. Subjects were classified according to alcohol consumption as nondrinkers, former drinkers, and current drinkers. Subjects were classified according to activity level as an exercise group, comprising those who exercised regularly at least once a week, and a non-exercise group. Body mass index (BMI) was calculated from body weight and height $\left(\mathrm{kg} / \mathrm{m}^{2}\right)$, and the degree of obesity was evaluated based on BMI: lean $\left(<18.5 \mathrm{~kg} / \mathrm{m}^{2}\right)$, normal range $\left(18.5-22.9 \mathrm{~kg} / \mathrm{m}^{2}\right)$, overweight $\left(23.0-24.9 \mathrm{~kg} / \mathrm{m}^{2}\right)$, and obese $\left(\geq 25.0 \mathrm{~kg} / \mathrm{m}^{2}\right)$. The cognitive function of participants was measured using the K-MMSE, which is widely used for screening the cognitive impairment of older adults in Korea. ${ }^{15)}$ Depression was measured with the 10-item short-form Center for Epidemiological Studies-Depression (CES-D10) scale, a screening tool for evaluating depression. Handgrip strength was measured by a handgrip dynamometer (TANITA Hand Grip Meter Blue 6103; Tanita Co., Tokyo, Japan). The grip strength of both hands was measured twice using a dynamometer, and the average was used.

\section{Fear of Falling}

FOF was measured by asking "Are you presently afraid of falling?" Previous studies have also used this question to evaluate FOF, with reliable results. ${ }^{11,16,17)}$ The FOF group was divided into three categories ac- 
cording to degree of fear: none, mild, and moderate. Although most previous studies compared FOF divided into two groups (presence or absence), our study was able to derive the linear relationship between degree of FOF and mortality by analyzing FOF divided into three categories (none, mild, and moderate).

\section{Statistical Analysis}

We analyzed the baseline characteristics of the participants by sex. The baseline characteristics of the study participants were analyzed by Student $\mathrm{t}$-test for continuous variables and by the chi-square test for categorical variables. Values are expressed as means \pm standard error or as percentages. To investigate the association between FOF and all-cause mortality, we used Cox proportional hazards models. Cox proportional

Table 1. Baseline characteristics of study participants $(\mathrm{N}=3,421)$

\begin{tabular}{|c|c|c|c|c|}
\hline Characteristic & Male $(n=1,474)$ & Female $(n=1,947)$ & Total $(n=3,421)$ & P-value* \\
\hline Age (y) & $71.5 \pm 0.1$ & $72.6 \pm 0.1$ & $72.4 \pm 0.1$ & $<0.001$ \\
\hline Education & & & & $<0.001$ \\
\hline Elementary school or less & $771(52.6)$ & $1,685(87.0)$ & $2,456(72.8)$ & \\
\hline Middle school & $217(14.4)$ & $137(7.0)$ & $354(10.0)$ & \\
\hline High school & $324(22.5)$ & 102(5.1) & $426(12.2)$ & \\
\hline University or above & $161(10.5)$ & $21(0.9)$ & $182(4.9)$ & \\
\hline Marital status & & & & $<0.001$ \\
\hline Living with spouse & $1,333(90.4)$ & $884(45.4)$ & $2,217(64.8)$ & \\
\hline Not living with spouse & $141(9.6)$ & $1,063(54.6)$ & 1,204 (35.2) & \\
\hline Smoking status & & & & $<0.001$ \\
\hline Current & $464(32.3)$ & $79(3.8)$ & $543(15.6)$ & \\
\hline Former $^{\dagger}$ & $387(25.9)$ & $18(0.9)$ & $405(11.2)$ & \\
\hline None & $623(41.8)$ & $1,850(95.3)$ & 2,473 (73.2) & \\
\hline Alcohol consumption & & & & $<0.001$ \\
\hline Current & $263(17.6)$ & $52(2.8)$ & $315(8.9)$ & \\
\hline Former & $779(53.6)$ & $227(11.7)$ & $1,006(29.0)$ & \\
\hline None & $432(28.8)$ & $1,668(85.5)$ & $2,100(62.2)$ & \\
\hline Regular exercise & $596(40.4)$ & $518(26.0)$ & $1,114(31.9)$ & $<0.001$ \\
\hline Fear of falling & & & & $<0.001$ \\
\hline Moderate & $204(13.6)$ & $564(29.0)$ & $768(22.7)$ & \\
\hline Mild & $577(38.9)$ & $993(51.2)$ & $1,570(46.1)$ & \\
\hline No & $693(47.5)$ & $390(19.8)$ & $1,083(31.2)$ & \\
\hline Falling history for 2 years & & & & $<0.001$ \\
\hline Yes & $44(2.8)$ & $163(8.3)$ & $207(6.0)$ & \\
\hline No & $1,430(97.2)$ & $1,784(91.7)$ & $3,214(94.0)$ & \\
\hline \multicolumn{5}{|l|}{ Chronic disease } \\
\hline Hypertension & $519(34.7)$ & $852(43.7)$ & $1,371(40.0)$ & $<0.001$ \\
\hline Diabetes mellitus & $233(15.7)$ & $323(16.2)$ & $556(16.0)$ & 0.74 \\
\hline Chronic lung disease ${ }^{\ddagger}$ & $66(4.5)$ & $55(2.9)$ & $121(3.6)$ & 0.02 \\
\hline Chronic liver disease ${ }^{\S}$ & $31(2.2)$ & $25(1.3)$ & $56(1.7)$ & 0.05 \\
\hline Heart diseasell & $103(6.7)$ & $157(7.9)$ & $260(7.4)$ & 0.20 \\
\hline Stroke & $76(5.0)$ & $53(2.9)$ & $129(3.8)$ & 0.02 \\
\hline Depression & $492(32.9)$ & $955(48.9)$ & $1,447(42.3)$ & $<0.001$ \\
\hline Handgrip strength (kg) & $28.2 \pm 0.2$ & $17.0 \pm 0.1$ & $21.9 \pm 0.1$ & $<0.001$ \\
\hline Korean-Mini Mental Status Evaluation & $25.4 \pm 0.1$ & $21.9 \pm 0.1$ & $23.5 \pm 0.1$ & $<0.001$ \\
\hline $\operatorname{BMI}\left(\mathrm{kg} / \mathrm{m}^{2}\right)$ & $23.1 \pm 0.2$ & $23.0 \pm 0.1$ & $23.1 \pm 0.1$ & 0.81 \\
\hline BMI category ${ }^{\#}\left(\mathrm{~kg} / \mathrm{m}^{2}\right)$ & & & & $<0.001$ \\
\hline Lean & $85(5.8)$ & $117(6.0)$ & $202(5.9)$ & \\
\hline Normal & $699(47.4)$ & $838(43.0)$ & $1,537(44.9)$ & \\
\hline Overweight & $396(26.9)$ & $413(21.2)$ & $809(23.6)$ & \\
\hline Obesity & $257(17.4)$ & $449(23.1)$ & $706(20.6)$ & \\
\hline
\end{tabular}

Values are presented as mean \pm standard error for continuous variables or number (\%) for categorical variables.

BMl, body mass index.

${ }^{*}$ P-values were determined via Student t-test analysis for continuous variables and chi-square test for categorical variables. ${ }^{\dagger}$ Former smokers were defined as those who do not smoke at present but have consumed more than five packs of cigarettes in the past. ${ }^{\ddagger}$ Chronic lung disease was defined as chronic obstructive pulmonary disease, including chronic bronchitis and emphysema. ${ }^{\$}$ Chronic liver disease was defined as all chronic liver diseases except fatty liver. "Heart disease included heart attacks, angina pectoris, myocardial infarction, congestive heart failure, or other heart disease. 'Depression were assessed using the 10-item short-form Center for Epidemiological StudiesDepression. "Lean, <18.5 (kg/m²); normal, 18.5-22.9 $\left(\mathrm{kg} / \mathrm{m}^{2}\right)$; overweight, 23.0-24.9 $\left(\mathrm{kg} / \mathrm{m}^{2}\right)$; obese, $\geq 25.0\left(\mathrm{~kg} / \mathrm{m}^{2}\right)$. 
hazards regression models were also used to identify the likelihood of death by degree of FOF. For samples satisfying the inclusion criteria, a complex sample file was constructed by applying weights to the sample, and then a complex Cox regression analysis was performed. The analysis was performed by all participants and was performed separately for each sex. Each model was adjusted for age, sex, history of falling, smoking status, BMI, physical activity, alcohol consumption, handgrip strength, depression, hypertension, diabetes mellitus, chronic lung disease, chronic liver disease, cardiovascular disease, and stroke; however, sex was excluded when analyzing by sex. All analyses were conducted using the IBM SPSS statistical package (IBM Corp., Armonk, NY, USA). A P-value of $<0.05$ was considered statistically significant.

\section{RESULTS}

The baseline characteristics of the study participants by sex are presented in Table 1. FOF was significantly higher in women for both mild FOF ( $n=993,51.2 \%)$ and moderate FOF ( $n=564,29.0 \%)$. Among the participants, $43.1 \%$ were men, and $56.9 \%$ were women. The mean age was $71.5 \pm 0.1$ years for men and $72.6 \pm 0.1$ years for women $(\mathrm{P}<0.001)$. The median body mass index was $23.1 \pm 0.1 \mathrm{~kg} / \mathrm{m}^{2}$, and there were no significant differences between men and women with respect to BMI. However, obesity (BMI $\geq 25.0 \mathrm{~kg} / \mathrm{m}^{2}$ ) rate was significantly higher in women $(23.1 \%)$ than in men $(17.4 \%)(\mathrm{P}<0.001)$. Hypertension was found in $40.0 \%$ of the patients; diabetes, $16.0 \%$, established cardiovas- cular disease, 7.4\%; and established stroke, 3.8\%. Stroke and chronic lung disease were significantly higher in men, and hypertension was significantly higher in women. However, there were no statistically significant differences in other medical conditions. The mean K-MMSE score (25.4 $\pm 0.1, \mathrm{P}<0.001)$, handgrip strength (28.2 $\pm 0.2, \mathrm{P}<0.001)$, the smoking and drinking rate of men was significantly higher than that of women. The rate of depression diagnosed based on CES-D10 was significantly higher in women $(\mathrm{P}<0.001)$. Of the participants, 2,338 (68.3\%) had a FOF and 207 (6.0\%) had had an incident of falling in the previous 2 years.

For the 3,421 subjects, during the follow-up period of approximately 8 years, the prevalence of all-cause mortality was $20.6 \%$ (705 participants: 388 men and 317 women). The mortality rate in men (26.3\%) was higher than that in women (16.3\%).

A significant association between FOF and mortality is shown in Table 2. After adjustment for age, sex, history of falling, smoking status, BMI, physical activity, alcohol consumption, handgrip strength, depression, diagnosis of hypertension, diabetes mellitus, chronic lung disease, chronic liver disease, cardiovascular disease, and stroke, the hazard ratios (HRs) of all-cause mortality for individuals with mild and moderate degrees of FOF were 1.25 times (95\% confidence interval [CI], 1.01-1.54) and 1.59 times (95\% CI, 1.23-2.05) that for those without FOF, respectively. After stratification by sex, both mild and moderate FOF groups had an increased mortality risk, but the mild FOF group was not statistically significant (male: HR, 1.24; 95\% CI, 0.961.60; female: HR, 1.38; 95\% CI, 0.92-2.07).

Table 2. Cox proportional hazard ratio of fear of falling on the mortality after adjusting for multiple variables

\begin{tabular}{|c|c|c|c|}
\hline Variable & Male $^{\dagger}$ & Female $^{\dagger}$ & Total $^{*}$ \\
\hline \multicolumn{4}{|l|}{ Fear of falling } \\
\hline No & 1.00 & 1.00 & 1.00 \\
\hline Mild & $1.24(0.96-1.60)$ & $1.38(0.92-2.07)$ & $1.25(1.01-1.54)$ \\
\hline Moderate & $1.71(1.23-2.39)$ & $1.59(1.02-2.46)$ & $1.59(1.23-2.05)$ \\
\hline \multicolumn{4}{|l|}{ Age $(y)$} \\
\hline$<75$ & 1.00 & 1.00 & 1.00 \\
\hline$\geq 75$ & $2.42(1.97-2.98)$ & $2.53(2.07-3.01)$ & $2.51(2.01-3.04)$ \\
\hline \multicolumn{4}{|l|}{ Sex } \\
\hline Female & & & 1.00 \\
\hline Male & & & $2.80(2.13-3.69)$ \\
\hline \multicolumn{4}{|l|}{ Falls } \\
\hline No & 1.00 & 1.00 & 1.00 \\
\hline Yes & $0.87(0.50-1.51)$ & $2.01(1.02-3.95)$ & $1.32(0.87-2.03)$ \\
\hline \multicolumn{4}{|l|}{ Smoker } \\
\hline None & 1.00 & 1.00 & 1.00 \\
\hline Former & $1.04(0.78-1.39)$ & $0.83(0.21-3.37)$ & $1.01(0.76-1.32)$ \\
\hline Current & $1.49(1.14-1.93)$ & $1.61(0.93-2.79)$ & $1.47(1.16-1.86)$ \\
\hline \multicolumn{4}{|c|}{ Body mass index $\left(\mathrm{kg} / \mathrm{m}^{2}\right)$} \\
\hline Lean & $1.40(0.96-2.04)$ & $1.48(1.02-2.17)$ & $1.38(1.06-1.80)$ \\
\hline Normal & 1.00 & 1.00 & 1.00 \\
\hline Overweight & $1.30(0.93-1.82)$ & $1.35(0.91-1.99)$ & $1.44(1.12-1.85)$ \\
\hline Obesity & $1.85(1.17-2.93)$ & $1.98(1.21-3.24)$ & $2.02(1.45-2.82)$ \\
\hline
\end{tabular}

Values are presented as hazard ratio (95\% confidence interval). Analyzed by Cox proportional hazards regression models.

${ }^{*}$ Adjusted for age, sex, history of falling, smoking status, body mass index, physical activity, alcohol consumption, handgrip strength, depression, hypertension, diabetes mellitus, chronic lung disease, chronic liver disease, cardiovascular disease, and stroke. ${ }^{\dagger}$ Sex was excluded when analyzing male and female. 
Figure 1 shows the Kaplan-Meier survival curves for these three groupings of FOF. The survival rate decreased with time in the group with FOF compared to the group without FOF.

Figure 2 shows the results of the subgroup analysis and is displayed in a schematic form as a forest plot. The mortality risk of the FOF group compared with the no FOF group was presented with the HR and 95\% $\mathrm{CI}$ in each subgroup. The association between FOF and mortality was consistent in subgroups defined according to age, sex, history of falling, smoking status, BMI, diagnosis of hypertension, and diabetes. FOF was a significant risk factor of mortality for patients without a previous history of falling after adjusting for other risk factors, as in the full

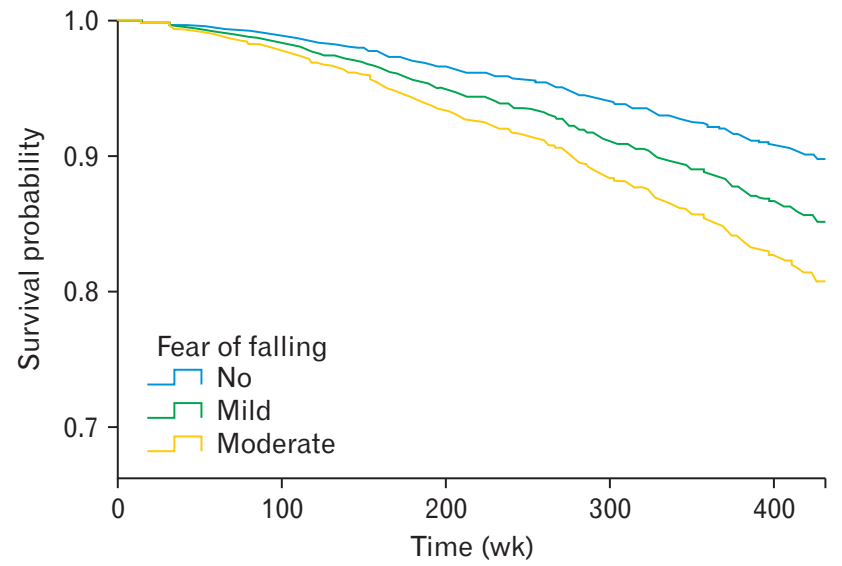

Figure 1. Kaplan-Meier plot showing the survival probability for all-cause mortality according to the degree of fear of falling. model, except for history of falling (HR, 1.65; 95\% CI, 1.27-2.13). In the group of patients who had previously experienced a fall, FOF had an increased risk of mortality, but was not statistically significant (HR, 3.80; 95\% CI, 0.22-14.80). The hazard ratio was also higher in groups with obesity (BMI $\geq 25.0 \mathrm{~kg} / \mathrm{m}^{2}$ ), but this was not statistically significant (HR, 1.19; 95\% CI, 0.59-2.42). In the group diagnosed with depression based on CES-D10, FOF increased the risk of mortality, but this was not statistically significant (HR, 1.40; 95\% CI, 0.96-2.03). The HRs for those diagnosed with stroke and cardiovascular disease were 1.10 (95\% CI, 0.30-3.17) and 1.56 (95\% CI, 0.62-3.95), respectively, but were not statistically significant. In the groups with MMSE $<23$ and $\geq 23$, the HRs were 1.49 (95\% CI, 0.98-2.27) and 1.56 (95\% CI, 1.11-2.20), respectively, and the former was not statistically significant.

\section{DISCUSSION}

In our study, FOF was a significant risk factor for mortality during the 8-year follow-up period in Korean elderly patients, and the mortality rate increased with the degree of FOF. In addition, subgroup analysis showed that these results were consistent in people who have not experienced previous falls.

FOF was recognized in the 1980s as a major health problem among older adults. Initially, FOF was considered as a post-fall syndrome, named ptophobia; however, subsequent studies found that FOF could also be identified in older adults, even those who have not experienced falls. ${ }^{1,2,11,18,19)}$ It has been reported that FOF results in several adverse consequences, including activity restriction, reduced social interactions, and a poor quality of life. It also results in further physical, psy-

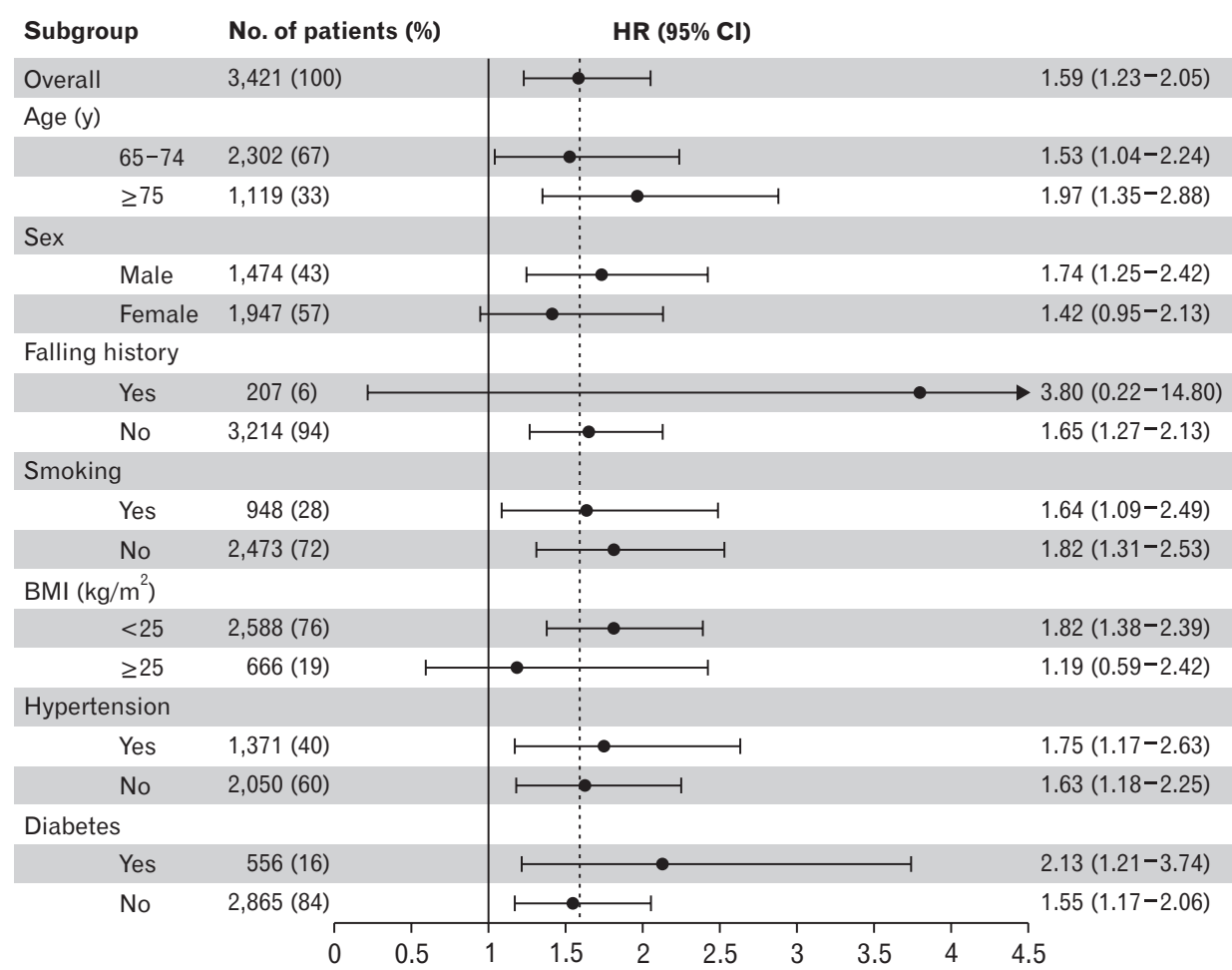

Figure 2. Forest plot of HRs by patient subgroups. The mortality risk of the mild and moderate FOF group compared with no FOF group was presented as $\mathrm{HR}$ with $95 \% \mathrm{Cl}$ in each subgroup. Analyzed by Cox proportional hazards regression models and in each subgroup analysis, adjusted for age, sex, history of falling, smoking status, BMI, hypertension, diabetes mellitus, chronic lung disease, liver disease, cardiovascular disease, and stroke, except for the corresponding subgroup variables for analysis. HR, hazard ratio; FOF, fear of falling; $\mathrm{Cl}$, confidence interval; BMl, body mass index. 
chological, mental, and social functional declines. ${ }^{2,10,20,21)}$

Anxiety disorders have been associated with a significantly increased mortality risk, and the co-occurrence of mood and anxiety disorders results in an additional increased risk of death. ${ }^{22)} \mathrm{A}$ recent meta-analysis indicated that approximately 5 million deaths worldwide are attributable to mood and anxiety disorders each year. ${ }^{23)}$ FOF is one of the phobic anxieties defined as excessive fear of falls, and phobic anxieties have been associated with cardiac mortality. A recent published meta-analysis reported that anxiety was associated with a $52 \%$ increase in the incidence of cardiovascular disease. ${ }^{24)}$ However, little is known about the mechanisms by which anxiety increases cardiovascular disease-associated mortality, but it is known that depression can increase cardiovascular disease-associated mortality by autonomic nervous system dysfunction, platelet dysfunction, and inflammatory mediators. ${ }^{25)}$ Some of these mechanisms have been used to explain the anxiety- and cardiovascular disease-associated mortality. However, further study is needed on the mechanism that FOF that contributes to mortality rate directly rather than as a confounding factor.

Restriction of physical activity and decline in physical function due to FOF could have an impact on mortality. Physical activity has been extensively studied because of its well-known effects on metabolic syndrome, insulin sensitivity, cardiovascular disease risk, and allcause mortality. ${ }^{26)}$ A study on the effects of physical activity on cardiovascular disease shows a correlation between physical activity and triglyceride, apolipoprotein B, high-density lipoprotein, low-density lipoprotein particle size, tissue plasminogen activity, and coronary artery calcium score. This suggests that cardiovascular mortality may be higher in patients with impaired physical activity due to FOF.

Moreover, FOF could be a result of the deterioration of physical function, such as muscle weakness, which is an indicator of frailty. Frailty is a prevalent and important geriatric syndrome associated with decreased survival. ${ }^{27)}$ The geriatric assessment of frailty provides clinically important information about functional status and survival of older adults. Age, number of chronic diseases, depressive mood, MMSE, falls, hospitalization, instrumental activity of daily living disability all contributed to frailty. ${ }^{28)} \mathrm{A}$ person with a FOF is more likely to be an elderly person with a frailty, and such an elderly person may have a higher risk of mortality. We assume that FOF can also be a tool for geriatric assessment of frailty, but further research is needed.

There has been a previous study of FOF and its association with mortality in the Shih-Pai area in Taiwan. ${ }^{29)}$ This 7-year follow-up longitudinal study comprised of 3,814 older adults aged 65 years and older who were living in the Shih-Pai area in Taiwan. In this study, FOF was associated with an increased risk of mortality (HR, 1.16; 95\% CI, 1.021.33) after adjusting for multiple variables, and this is consistent with the results of our study. However, the study was conducted only with participants from a single community in Taiwan, unlike our study, which covered the entire geographical area of Korea. In addition, the Taiwan study did not evaluate the FOF according to degree, so it could not analyze the association between the degree of FOF and mortality.
Nevertheless, several limitations should be considered in interpreting the results of our study. First, the percentage of people with FOF was overestimated compared with previous studies. FOF has been reported to occur in about $30 \%$ to $65 \%$ of community-dwelling older adults aged $>60$ years, according to previous studies. ${ }^{2,5)}$ In the literature, the prevalence of FOF has been consistently higher among women than among men; ${ }^{2,5,10)}$ however, it reached $80 \%$ in women and $50 \%$ in men in this study. This may have been because FOF was categorized by degree (none, mild, or moderate) instead of presence or absence.

Second, there was a selection bias due to loss at follow-up and unknown dates of death. We tried to reduce the selection bias, but we could not eliminate it entirely, because the bias was introduced by the sample collection process.

Third, there were differences in baseline characteristics between men and women. Because of these differences, the results with respect to mortality were different between men and women, showing different results in the subgroup analysis.

Fourth, in a group of participants who had previously experienced a fall, FOF had an increased risk of mortality, but this not statistically significant. This is because the percentage of participants who had previously experienced a fall was only $6 \%$, so caution is needed in interpreting this result.

Furthermore, we did not perform cause-specific mortality analyses. The causes of death were collected at each time from the family or dwellers after death of participants and not by the Cause of Death Registry. For this reason, deaths from diseases such as cancer, cardiovascular disease, or death from external causes were not all exactly evaluated.

Despite these limitations, our study has several strengths. First, KLoSA is a nationwide survey with a sample of 10,254 subjects in 2006, and $80 \%$ participated until 2014. The large sample size and 8-year follow-up contributed significantly towards elucidating the relationship between FOF and mortality in the elderly.

We were able to demonstrate a relationship between mortality and the degree of FOF. Previous studies classified FOF into two categories, by either presence or absence of FOF, whereas this study classified it into three categories according to degree (none, mild, and moderate). As a result, we were able to demonstrate a linear relationship of FOF and mortality according to its degree of FOF. The higher the degree of FOF, the higher the mortality, which further demonstrated that FOF is a significant risk factor for mortality in the elderly.

This study showed that FOF is a significant risk factor for mortality in Korean elderly. However, further studies are needed to determine the mechanism by which FOF increases mortality.

\section{CONFLICT OF INTEREST}

No potential conflict of interest relevant to this article was reported. 


\section{FUNDING}

This paper was supported by Wonkwang University in 2018.

\section{ORCID}

Ari Lee: https://orcid.org/0000-0002-2876-4198

Jungun Lee: https://orcid.org/0000-0001-8580-1445

Gyumin Lee: https://orcid.org/0000-0002-7044-7452

Dong Ryul Lee: https://orcid.org/0000-0001-7255-4561

\section{REFERENCES}

1. Austin N, Devine A, Dick I, Prince R, Bruce D. Fear of falling in older women: a longitudinal study of incidence, persistence, and predictors. J Am Geriatr Soc 2007;55:1598-603.

2. Scheffer AC, Schuurmans MJ, van Dijk N, van der Hooft T, de Rooij SE. Fear of falling: measurement strategy, prevalence, risk factors and consequences among older persons. Age Ageing 2008;37:19-24.

3. Tinetti ME, Richman D, Powell L. Falls efficacy as a measure of fear of falling. J Gerontol 1990;45:P239-43.

4. Vellas BJ, Wayne SJ, Romero LJ, Baumgartner RN, Garry PJ. Fear of falling and restriction of mobility in elderly fallers. Age Ageing 1997;26: 189-93.

5. Zijlstra GA, van Haastregt JC, van Eijk JT, van Rossum E, Stalenhoef PA, Kempen GI. Prevalence and correlates of fear of falling, and associated avoidance of activity in the general population of communityliving older people. Age Ageing 2007;36:304-9.

6. Zijlstra GA, van Haastregt JC, van Rossum E, van Eijk JT, Yardley L, Kempen GI. Interventions to reduce fear of falling in community-living older people: a systematic review. J Am Geriatr Soc 2007;55:603-15.

7. Deshpande N, Metter EJ, Lauretani F, Bandinelli S, Guralnik J, Ferrucci L. Activity restriction induced by fear of falling and objective and subjective measures of physical function: a prospective cohort study. J Am Geriatr Soc 2008;56:615-20.

8. Visschedijk J, Achterberg W, Van Balen R, Hertogh C. Fear of falling after hip fracture: a systematic review of measurement instruments, prevalence, interventions, and related factors. J Am Geriatr Soc 2010; 58:1739-48.

9. Rossat A, Beauchet O, Nitenberg C, Annweiler C, Fantino B. Risk factors for fear of falling: a cross-sectional population-based study. J Am Geriatr Soc 2009;57:1304-6.

10. Clemson L, Kendig H, Mackenzie L, Browning C. Predictors of injurious falls and fear of falling differ: an 11-year longitudinal study of incident events in older people. J Aging Health 2015;27:239-56.

11. Friedman SM, Munoz B, West SK, Rubin GS, Fried LP. Falls and fear of falling: which comes first?: a longitudinal prediction model suggests strategies for primary and secondary prevention. J Am Geriatr Soc 2002;50:1329-35.

12. Murphy SL, Williams CS, Gill TM. Characteristics associated with fear of falling and activity restriction in community-living older persons. J
Am Geriatr Soc 2002;50:516-20.

13. Uemura K, Shimada H, Makizako H, Doi T, Tsutsumimoto K, Yoshida $\mathrm{D}$, et al. Effects of mild and global cognitive impairment on the prevalence of fear of falling in community-dwelling older adults. Maturitas 2014;78:62-6.

14. Park JH, Lim S, Lim J, Kim K, Han M, Yoon IY, et al. An overview of the Korean Longitudinal Study on Health and Aging. Psychiatry Investig 2007;4:84-95.

15. Kang Y, Na DL, Hahn S. A validity study on the Korean mini-mental state examination (K-MMSE) in dementia patients. J Korean Neurol Assoc 1997;15:300-8.

16. Mann R, Birks Y, Hall J, Torgerson D, Watt I. Exploring the relationship between fear of falling and neuroticism: a cross-sectional study in community-dwelling women over 70. Age Ageing 2006;35:143-7.

17. Murphy SL, Dubin JA, Gill TM. The development of fear of falling among community-living older women: predisposing factors and subsequent fall events. J Gerontol A Biol Sci Med Sci 2003;58:M943-7.

18. Murphy J, Isaacs B. The post-fall syndrome: a study of 36 elderly patients. Gerontology 1982;28:265-70.

19. Tinetti ME, Speechley M, Ginter SF. Risk factors for falls among elderly persons living in the community. N Engl J Med 1988;319:1701-7.

20. Reelick MF, van Iersel MB, Kessels RP, Rikkert MG. The influence of fear of falling on gait and balance in older people. Age Ageing 2009;38: 435-40.

21. Tomita Y, Arima K, Kanagae M, Okabe T, Mizukami S, Nishimura T, et al. Association of physical performance and pain with fear of falling among community-dwelling Japanese women aged 65 years and older. Medicine (Baltimore) 2015;94:e1449.

22. Meier SM, Mattheisen M, Mors O, Mortensen PB, Laursen TM, Penninx BW. Increased mortality among people with anxiety disorders: total population study. Br J Psychiatry 2016;209:216-21.

23. Walker ER, McGee RE, Druss BG. Mortality in mental disorders and global disease burden implications: a systematic review and metaanalysis. JAMA Psychiatry 2015;72:334-41.

24. Batelaan NM, Seldenrijk A, Bot M, van Balkom AJ, Penninx BW. Anxiety and new onset of cardiovascular disease: critical review and metaanalysis. Br J Psychiatry 2016;208:223-31.

25. Joynt KE, Whellan DJ, O'Connor CM. Depression and cardiovascular disease: mechanisms of interaction. Biol Psychiatry 2003;54:248-61.

26. Ahmed HM, Blaha MJ, Nasir K, Rivera JJ, Blumenthal RS. Effects of physical activity on cardiovascular disease. Am J Cardiol 2012;109:28895.

27. Shamliyan T, Talley KM, Ramakrishnan R, Kane RL. Association of frailty with survival: a systematic literature review. Ageing Res Rev 2013;12:719-36.

28. Shim EY, Ma SH, Hong SH, Lee YS, Paik WY, Seo DS, et al. Correlation between frailty level and adverse health-related outcomes of community-dwelling elderly, one year retrospective study. Korean J Fam Med 2011;32:249-56.

29. Chang HT, Chen HC, Chou P. Fear of falling and mortality among community-dwelling older adults in the Shih-Pai study in Taiwan: a longitudinal follow-up study. Geriatr Gerontol Int 2017;17:2216-23. 